\title{
The last natural nuclear fission reactor
}

Sir - The last known natural fission reactor on Earth is likely to be mined this year. Because these natural reactors are unique, at least one should be preserved for present and future research programmes.

The uranium deposits of Gabon host high-grade ores in which nuclear fission reactions occurred 2 billion years ago. These reactors have been studied since their discovery in 1972 because they represent a unique opportunity to describe and understand the behaviour of actinides and fission products in a geological system. The results of these studies have been used to establish analogies between the behaviour of geological systems and materials in natural reactors, and the materials and processes that can lead to the containment or migration of fission products and actinides in nuclear waste repositories (Final report EUR 16857: Oklo-Natural Analogue, Office for Official Publications of the European Communities, 1996). The natural reactors also provide unique information on the processes by which natural systems can reach criticality. There are no other known deposits of this type.

All the reactors except one are located in the most important uranium deposit of Gabon's Franceville basin, at Oklo.

Fourteen reactors have been discovered in this deposit, all of which are now partially or completely mined. This deposit will be completely mined out soon, in 1998.

Future work on these reactors will therefore have to rely on previously collected samples, many of which are poorly documented and are out of their geological context. It will therefore not be possible to study the behaviour and migration of fission products and actinides in the near-field and far-field environments of these reactors.

Such work is still possible, however, in a reactor located in the very small uranium deposit of Bangombé $30 \mathrm{~km}$ from Oklo. This reactor has not been mined. It is only 12 metres deep and has therefore been affected by near-surface weathering, but initial results show that the reactor is well preserved and that the effects of weathering on the distribution of actinides and fission products can be discerned. A European research programme (Oklo-Natural analogue, Phase II) has been established for a coordinated and interdisciplinary study of this reactor in order to complete hydrogeochemical and geochemical modelling of the geological processes that affect radionuclide migration (for example, high-temperature hydrothermal alteration, low-temperature meteoric alteration, migration and sorption along fracture networks, and the mineralogy and geochemistry of the radionuclide-bearing phases).

The probability of other reactors on the Earth is very small because of the rather special conditions required for nuclear fission reactions to occur:

(1) The uranium deposit hosting the reactor must be older than $1,800 \mathrm{Myr}$, in order to have an adequately high ${ }^{235} \mathrm{U} /{ }^{238} \mathrm{U}$ ratio (the half-life of uranium-235 is 700 million years, as compared with 4.5 billion years for uranium-238).

(2) The deposit must have a low content of elements such as boron and vanadium, which are neutron absorbers that decrease the possibility of the fission chain reaction beginning and being sustained.

(3) In order to preserve the reactor deposits for a long period, the deposit must be located in a very stable basin, protected from geological events that could lead to the remobilization of the uranium involved in the nuclear process. To our knowledge, this situation is not known to have existed anywhere else on the planet. Thus there is every reason to expect that the Bangombé reactor is the very last on the Earth.

We propose that this unique, scientifically important deposit be preserved for present and future research. This deposit is no less unique, and certainly more irreplaceable, than the most valued specimens from the Moon and Mars. Yet the deposit consists of only 100-200 tonnes of commercially viable uranium, so there is no compelling economic need to mine it. Prudence and responsibility require that careful consideration be given to the preservation of this last natural reactor. F. Gauthier-Lafaye

Centre de Géochimie de la Surface, CNRS,

1 rue Blessig,

67084 Strasbourg,

France

e-mail:gauthier@illite.u-strasbg.fr

This note is signed by the scientists of the Technical Committee of the European Program (Oklo-Natural Analogue, Phase II):

P-L. Blanc, J. Bruno, F. Gauthier-Lafaye,

L. Griffault, E. Ledoux, D. Louvat,

V. Michaud, M. Montoto, V. Oversby,

L. Perez del Villar, J. Smellie

\section{Who cares what's new?}

Sir - An exponential increase in the use of the word 'novel' by scientists to describe their work has been revealed in a statistical analysis of the Medline database by S. H. Friedman and J. O. M. Karlsson (Nature 385, $480 ; 1997)$. We have carried out a similar analysis of the MathSci and PsycLIT databases searching for titles and abstracts containing the words 'novel' or 'new'.

The figure plots frequency of the words 'novel' and 'new' as a proportion of total papers. The Medline data are also shown for comparison.

In contrast with the exponential increase seen in the Medline database, the use of the word 'novel' in the PsycLIT database has remained essentially constant over the past twenty years. There is only a slight increase in use seen in the MathSci database.

The use of the word 'novel' in the
PsycLIT and MathSci databases is well below that in the Medline database. By contrast the use of the word 'new' in the MathSci database showed a tenfold increase between 1975 and 1980 .

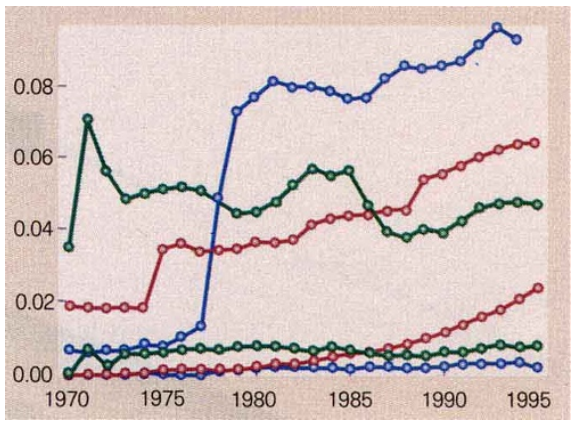

Proportion of papers per year in the indicated databases that contain the words 'novel' (lower points) and 'new' (upper points) in the title or abstract. Blue denotes MathSci, red Medline and green PsycLIT.
There is also a significant increase in use of 'new' seen in the Medline database, but in the period 1980-94 this use has remained well below that in the MathSci database. The use of the word 'new' in the PsycLIT database has remained essentially constant over the past twenty years.

A possible explanation is that what is 'new' to the mathematical scientists is both 'new' and 'novel' to the biomedical scientists but neither here nor there to the psychologists and behavioural scientists.

\section{Murray T. Batchelor}

Department of Mathematics, Australian National University,

Canberra ACT 0200, Australia

Bruce I. Henry

\section{Simon D. Watt}

Department of Applied Mathematics,

University of New South Wales

Sydney NSW 2052,

Australia 